\title{
A Boy with Dental Phobia and Severe Syncope
}

\author{
Inmaculada Palanca-Maresca ${ }^{1}$ - M. Azul Forti-Buratti ${ }^{1}$ (D) $\cdot$ Ana Usano ${ }^{2}$
}

Received: 26 April 2018 / Accepted: 2 April 2019 / Published online: 24 April 2019

(C) Dr. K C Chaudhuri Foundation 2019

To the Editor: In children, vasovagal syncope is the most frequent syncope, provoked by an emotion or orthostatic stress. The cardioinhibitory vasovagal reflex syncope with asystole with a specific trigger (CVRS) is unusual. Diagnosis is based on a complete clinical history, physical examination and electrocardiogram (ECG). Neurologic and cardiologic assessments are sometimes needed. Asystole is an uncommon cause [1].

A 4-y-old boy presented with a history of 2-3 episodes per week of syncope-presyncope during the 4 months prior to the initial assessment, with seizures in 3 of them. Syncopes occurred at school and at home when facing verbal or visual stimuli of tooth loss or small wounds in oral cavity.

There was nothing remarkable in his personal history, physical examination or studies. During the Tilt-table test he presented with $42 \mathrm{~s}$ of asystole with generalized hypertonia and spontaneous urination when the Pediatrician described a dental extraction. Basic Cardiopulmonary resuscitation (CPR) was started and he completely recovered.

He was diagnosed with CVRS (with dental phobia) and was referred to Child and Adolescent Psychiatry (CAP).

He was treated with 16 sessions of Cognitive behavioral therapy (CBT) and $0.5 \mathrm{mg}$ Lorazepam $1 \mathrm{~h}$ prior to the sessions. The treatment took place in Accident and Emergency department (A\&E) and parents were CPR trained. He continued his follow-up with the Cardiologist and $2.5 \mathrm{y}$ later he lost all his teeth not showing any symptom.

Fifteen percent of children would present at least one syncope episode before reaching adolescence, representing up to 3\% of visits to A\&E [2]. Also, $6.1 \%$ of children present dental fear [3].

Inmaculada Palanca-Maresca

inmaculada.palanca@salud.madrid.org

1 Department of Psychiatry, Hospital Universitario Puerta de Hierro, calle Manuel de Falla 1, 28222 Majadahonda, Spain

2 Department of Pediatric Cardiology, Hospital Universitario Puerta de Hierro, Majadahonda, Spain
There are not enough studies that recommend a drug to treat these patients [2]. According to the latest guidelines, cardiac stimulation is not indicated in children and adolescents with CVRS [2]. The most effective treatment in CVRS is avoiding the trigger or treating the underlining phobia [2]. Children from 4 to $7 \mathrm{y}$ with anxiety disorders were treated with age-adapted CBT, with promising results [4].

In this case, his phobia was generalized to daily life and with extremely unusual and severe consequences. Given his age and clinical characteristics, CBT was chosen. The response has been complete. This case illustrates the importance of psychological therapy in medical pathology and how essential is liaison between CPA and Pediatrics.

\section{Compliance with Ethical Standards}

Conflict of Interest None.

\section{References}

1. Strickberger SA, Benson DW, Biaggioni I, et al. AHA/ACCF scientific statement on the evaluation of syncope: from the American Heart Association Councils on Clinical Cardiology, Cardiovascular Nursing, Cardiovascular Disease in the Young, and Stroke, and the Quality of Care and Outcomes Research Interdisciplinary Working Group; and the American College of Cardiology Foundation: in collaboration with the Heart Rhythm Society: endorsed by the American Autonomic Society. Circulation. 2006;113:316-27.

2. Moya A, Sutton R, Ammirati F, et al. Guidelines for the diagnosis and management of syncope (version 2009). Eur Heart J. 2009;30: 2631-71.

3. Olak J, Saag M, Honkala S, et al. Children's dental fear in relation to dental health and parental dental fear. Stomatologija. 2013;15:26-31.

4. Hirshfeld-Becker DR, Masek B, Henin A, et al. Cognitive behavioral therapy for 4- to 7-year-old children with anxiety disorders: a randomized clinical trial. J Consult Clin Psychol. 2010;78:498-510.

Publisher's Note Springer Nature remains neutral with regard to jurisdictional claims in published maps and institutional affiliations. 